\title{
Más sobre Cervantes, Plutarco y los cínicos: una anécdota de Alcibíades y el Coloquio de los perros
}

\begin{abstract}
ADRIÁN J. SÁEZ*
La tradición clásica se presenta de muy diversas formas en la obra de Cervantes, ya sea en intertextos, referencias explícitas e implícitas, traducciones, etc. De hecho, su obra novelística se enmarca dentro de moldes grecolatinos, ya que tanto su primer como su último relato extenso, La Galatea y el Persiles, se inspiran en géneros de raigambre grecolatina, el libro de pastores y la novela helenizante, de lo cual el novelista es consciente al afirmar su emulación de las Etiópicas en el prólogo de las Novelas ejemplares (p. 81) ${ }^{1}$. Tampoco el Quijote es ajeno al mundo clásico, porque pese a constituir $a$ priori una parodia de la novela de caballerías, hace gala de una intertextualidad con la cultura grecolatina «tanto más significativa cuanto la novela no se enmarca en un género de raíz clásica» (Barnés Vázquez, 2009 y 2010). Asimismo, el Viaje del Parnaso, las Novelas ejemplares, su poesía y su teatro contienen ecos mitológicos y recrean estructuras y géneros nacidos en la Antigüedad.

* Université de Neuchâtel, Suiza.

1. Ver Barnés Vázquez (2009); Sáez (2011 y en prensa), con bibliografía. Empleo «novela helenizante» y no «novela bizantina» como es usual siguiendo a Torres (2009). Sánchez Jiménez (2011) defiende la trayectoria literaria de Cervantes como una imitación flexible de la rota Virgilii que planteaba una jerarquía progresiva, que en su caso estaría conformada por La Galatea, el Quijote y el Persiles: «un proceso humanista de aprendizaje y mejora estilística que no tenía por qué seguir exactamente la producción virgiliana» (p. 480). Todas las citas son por la edición de García López; indico solo la página. Para el Quijote sigo la edición dirigida por Rico, indicando parte y capítulo. Desarrollo sus datos en la bibliografia final.
\end{abstract}




\section{CULTURA Y RELACIONES LITERARIAS: CERVANTES Y PLUTARCO}

Tradicionalmente se ha pensado que Cervantes era un «ingenio lego», como se declara él mismo en el Viaje del Parnaso, imagen difundida desde los trabajos de Castro y hoy ya descartada. Otro cantar es conocer qué libros leyó o cuáles formaban parte de su biblioteca. Se sabe que adquirió una serie de obras en una subasta en 1590 y es razonable pensar que heredó los libros que poseía su padre a su muerte en 1585 , conocidos por un documento de embargo de 1552, aunque entre ambas fechas pudieron darse cambios ${ }^{2}$. Eisenberg (1987 y 2001) ha tratado en varias ocasiones de reconstruir su biblioteca, aquella que tendría en 1616, que constaría de más de 200 libros, mas su tesis carece de apoyo suficiente: las menciones de autores, obras, personajes y las citas textuales no indican necesariamente un contacto directo, y desde luego podía conocer otros que no menciona. Por otra parte, podía tener acceso a la letra impresa gracias a amigos, mecenas o su librero Francisco de Robles.

Así pues, la biblioteca de Cervantes carece de luz suficiente, pero tampoco es materia que pretenda abordar. Las tres posibles vías de conocimiento de que disponía Cervantes eran la lectura directa de fuentes primarias, la transmisión indirecta por fuentes secundarias (misceláneas como el Jardín de flores curiosas de Torquemada o la Silva de varia lección de Pero Mexía, etc.) y los saberes comunes de su época. Otro asunto espinoso es si Cervantes era capaz de leer los originales latinos. Eisenberg (2001: 88) opina que «no demuestra conocer ningún autor clásico que no existiera en traducción». Ahora bien, su educación con López de Hoyos y los jesuitas permite sospechar (como mínimo) que era capaz de leer latín, a lo que debe sumarse un marcado autodidactismo que contribuiría a cubrir algunas de las lagunas de su formación preuniversitaria ${ }^{3}$.

Aquí entra en escena Plutarco de Queronea, autor predilecto del humanismo cristiano (Vega, 2003: 263). A él se deben las Vidas paralelas, un conjunto de 22 biografías de personajes ilustres de Grecia y Roma que Plutarco hermana por cualidades o carreras semejantes y que constituyen ejemplos edificantes dignos de ser imitados. Fueron muy conocidas en España, espe-

2. Los libros de la subasta eran «cuatro libritos dorados de letra francesa», sin identificar, y una Historia de Santo Domingo por treinta reales, que Astrana Marín identifica «casi seguro» como la Primera parte de la Historia General de Santo Domingo y de su Orden de Predicadores, escrita por fray Hernando del Castillo (Madrid, Francisco Sánchez, 1584). Ver Astrana Marín (1948-1958, vol. 4: 463-464). La hipótesis de la herencia es de Eisenberg (1987: 271). Entonces poseía «tres libros, el uno de Antonio y el otro de práctica de cirugía, y otro libro de las cuatro enfermedades» (Rodríguez Marín, 1947: 213).

3. Ver Close (2005); Márquez Villanueva (2005); Barnés Vázquez (2009: 24-27). Tanto Close (2005) como Lerner (2008) subrayan la presencia de la Naturalis historia de Plinio el Viejo en la obra de Cervantes. Ver también Marasso (1947: 222-224). Respecto al prodigio de los perros parlantes del Coloquio de los perros he señalado en otro lugar (Sáez, 2011) que tanto Plinio (Historia natural, VIII, 153) como Tito Livio (Historia de Roma, III, 10, 6 y 35, 21, 4), entre otros, se asombran de un acontecimiento similar. 
cialmente a partir de la versión en romance realizada por Alfonso López de Palencia en base a traducciones latinas y no al original griego, que fue publicada en dos volúmenes (Sevilla, Cuatro compañeros alemanes, 1491), con reediciones en 1508 y $1592^{4}$. Se documenta también Las vidas de los ilustres y excelentes varones griegos y romanos (Colona, s.e., 1562) en traducción de Juan Castro de Salinas, y otras versiones castellanas parciales con solo alguno de los relatos y muy aderezadas de interpolaciones y comentarios personales: Francisco de Enzinas, El primero volumen de las vidas de los ilustres y excelentes varones griegos y romanos (1551), que contiene las peripecias de Teseo, Rómulo, Licurgo, Numa, Solón y Publícola, más Temístocles y Camilo, atribuidas a Enzinas o a Gracían de Alderete; o Francisco de Quevedo y su Vida de Marco Bruto (1644). Mientras tanto, los Moralia o Escritos morales, que agrupan textos muy variados (filosofía, religión, retórica, política, etc.), fueron ampliamente traducidos durante el Renacimiento ${ }^{5}$. Tampoco pueden olvidarse los acordes de Plutarco que se escuchan en la emblemática, la iconografía y los tratados de educación de príncipes de los siglos XVI Y XVII ${ }^{6}$. En palabras de Pérez Jiménez (2003a: 176), en numerosos libros áureos

están los ejemplos de las Vidas paralelas que ofrecen modelos de virtud moral y política a los clérigos e intelectuales erasmistas y contrarreformistas, empeñados en la educación de príncipes y gobernadores. Pero también lo están, y en mayor grado, los tratados de Moralia, obra de amplio espectro cultural en la que dominan ensayos o diálogos pedagógicos, teológicos, filosóficos, éticos, de religión y colecciones de apotegmas, tan apropiados para el género como para las pretensiones didácticas de sus cultivadores.

De vuelta por un momento a la educación de Cervantes, no está de más recordar que la ratio studiorum de los jesuitas incluía a Plutarco entre sus autores de cabecera: se profundizaba en sus obras en cuarto curso y se insistía en su valor didáctico, en equilibrio con las enseñanzas morales de la patrística (Muñoz Gallarte, 2006: 197) ${ }^{7}$. Además, Ramón Palerm (1999) ha analizado las conexiones entre los conceptos de Historia que manejaban Cervantes y Plutarco.

En su batida sobre la tradición clásica Barnés Vázquez indica que en el Quijote hay doce referencias explícitas o implícitas a Plutarco, siendo el décimo autor más presente, a gran distancia de Virgilio (94 entradas), pero

4. López Férez (1994). Lasso de la Vega (1962: 473-483) ha demostrado que se valió de la edición veneciana de 1478 que se encuentra en la Biblioteca Nacional de España (I-573). Ver Torrent (2008).

5. Cercana a Cervantes está la traducción de Diego Gracián, que cuenta con dos ediciones: Alcalá de Henares, Juan de Brocar, 1548; y Salamanca, Alejandro de Cánova, 1571, empleada aquí. Ver Pérez Jiménez (1990); Morales Ortiz (2000).

6. Ver Pérez Jiménez (2003a, 2003b, 2003c, 2005a, 2005b y 2006).

7. En la relación de las ediciones de Plutarco conservadas en el Seminario de Cuenca hay varias traducciones latinas y romances de las Vidas y de los Moralia. 
cercano a Séneca (19) y seguido por Tito Livio (10), Esopo (9), Catón (9) y César (8); explícitamente solo documenta una referencia a Plutarco, sin ninguna traducción ad litteram en el cuerpo del texto (Barnés Vázquez, 2009: 28-30 ${ }^{8}$. Dentro de este catálogo se hallan algunas referencias a las Vidas paralelas:

1. Ya en el prólogo se lee: «si [tratáredes] de capitanes valerosos, el mesmo Julio César os prestará a sí mismo en sus Comentarios, y Plutarco os dará mil Alejandros» (p. 16), clara referencia a las Vidas paralelas donde se halla la biografía del héroe macedonio y que para Lerner (2008: 16) sirve como «ejemplo de falsos conocimientos y erudición superficial».

2. En el escrutinio de la biblioteca (I, 6), el cura recuerda el aprecio que Alejandro Magno sentía hacia la Ilíada, de la que guardaba un ejemplar en el cofre que obtuvo tras su victoria en Iso contra Darío en el año 333 a. C., que puede hallarse en el libro octavo de las Vidas paralelas.

3. En la sentencia «retirar no es huir» $(\mathrm{I}, 23)$ de Sancho se ha visto una inversión de la frase de Bruto al suicidarse: «Huir, sin duda; mas no por pies, sino por manos» (Vidas paralelas, «Bruto», XIII) (López Fanego, 1977).

4. La referencia a la amistad que debe llegar usque ad aras que refiere Lotario (I, 33) es el clásico adagio atribuido a Pericles, uno de los biografiados por Plutarco.

5. El comentario sobre el deseo de Anselmo de que su mujer fuese una «segunda Porcia» (I, 34), cuyo ejemplo se halla en las Vidas.

6. La anécdota de Alejandro Magno y Apeles (II, 59), único que podía retratarle, puede proceder de Plinio el Viejo, Historia Naturalis, VII, 37 y 35, 10; Mexía, Silva de varia lección, II, 18, pero se halla apuntada en la Vida de Alejandro, 4, 3.

\section{DE LA ANÉCDOTA A LA NOVELA}

Precisamente en esta obra se encuentra el pasaje que dio pie al presente ensayo. En la traducción de Alfonso de Palencia, que bien pudo conocer Cervantes, reza asi ${ }^{9}$ :

Dicen que Alcibíades había comprado un can por setenta minas y cortada la cola le deja ir por toda la cibdad. Y pareciendo este tal negocio cosa

8. Aclara que las referencias explícitas son citas de su nombre, un texto suyo o un hecho de su vida, mientras que las implícitas son hipótesis más o menos plausibles de los estudiosos. Este muestrario se redondea con otro eco plutarquiano presente en la aprobación de José de Valdivielso (p. 610).

9. Una traducción moderna lee: «A un perro que tenía, de excelente tamaño y belleza y que había comprado por setenta minas, le cortó el rabo, que era muy hermoso. Los amigos lo reprendían y le decían que todos estaban que mordían por el perro y que lo criticaban, por lo que se echó a reír y dijo: "Entonces está pasando lo que deseo; pues quiero que los atenienses hablen de esto, para que no digan algo peor sobre mí"» (Alcibiades, IX, p. 141). 
loca y desvariada, amonestábanle los amigos diciéndole todo lo que murmuraba la gente. Y él, riendo, les respondió: «Así sucedió la cosa como yo quería. Quise dar esta ocasión a los atenienses para que fablasen en esto y a causa de esta novedad cesasen de fablar otras cosas peores que de mí suelen decir y oír» (fol. 70v.).

También se refiere en las Máximas de reyes y generales (en Moralia), texto al alcance en el Siglo de Oro:

Teniendo un perro muy hermoso que había mercado en siete mil dracmas, le cortó la cola y soltole por la ciudad, diciendo: «Porque los atenienses digan esto solo de mí y no busquen cosa que hablar». Conoscía el ingenio del vulgo que de buena gala hablan mal de los varones excelentes, y por eso les quería dar qué murmurar en más liviana materia (p. 13).

Las peripecias de Alcibíades (ca. 450-404 a. C.) eran bien conocidas entre el público culto. Hábil estadista ateniense educado por Pericles y Sócrates, su vida pública contrastaba con su turbulento comportamiento personal porque, inmerso en varias polémicas desde su juventud, fue alternativamente considerado héroe y traidor a la patria, debido a que unas veces salvaba a Atenas y otras alentaba los ataques contra la polis. La composición de la Vida de Alcibiades se vio facilitada por la abundante documentación existente; gracias a su relación con Sócrates estaba presente en textos de Platón (Banquete), Tucídides (Historia de la guerra del Peloponeso), Jenofonte (Helénicas), las perdidas historias de Éforo y Teopompo, un discurso de Andócides y repetidas menciones en Aristófanes. Así, Plutarco pudo relatar su vida desde su juventud hasta su muerte, entre dones admirables y vicios como la ambición, las pretensiones tiránicas, la osadía y la licencia amorosa, etc., en uno de los pocos ejemplos que no deben imitarse de esta serie de biografías, en claro contraste con su par Coriolano (Crespo, 1999: 357-359).

La anécdota citada ilustra su contradictoria personalidad (Rodríguez Blanco et al., 1987: 78-81) ${ }^{10}$. A todas luces, reviste los atributos de una historia fantástica que cierra con llave de oro la primera sección de la biografía, a la vez que confirma que Alcibíades no duda en cometer hechos generalmente recordados como transgresores, enlaza con su liberalidad excesiva y su respuesta apunta lo que va a ocurrir después en su Vida: la gente va a rememorar y relatar peores acciones suyas (Verdegem, 2010: 162).

Solamente se puede conjeturar que Cervantes lograse leer alguna de las fuentes mencionadas, pero dada la popularidad de las Vidas y las Moralia de Plutarco y la difusión de sus traducciones no sería nada extraño. Sea como fuere, a través de las polianteas también pudo tener acceso a este episodio ${ }^{11}$. Por ejemplo, entre las diversas menciones que se cuentan de Alcibíades en la

10. Donde se añaden otros dos episodios: el temor de Pericles de que Alcibíades fuera un mal ejemplo para su hermano; y la estafa de Alcibíades a Diomedes, otra muestra de cinismo.

11. Para su importancia en Cervantes, ver Lerner (2008). No se menciona en el Tesoro de Covarrubias, que remite a Plutarco. 
célebre Officina de Textor (I, esp. 77, 87, 135, 181), muy utilizada por Lope de Vega, se encuentra también el pasaje en cuestión:

Alcibiades inusitata magnitudine canem emit LXX. minis, quem amputata cauda spectante populo ducebat vinctum, ut garrulorum et importunae loquacitatis hominum linguas ea in re occuparet, ne quid deterius in eius nomen obloquerentur. Plutarchus testis (I, p. 358).

Con todo, existían otros cauces posibles por los que pudo tener noticia de este personaje: el diálogo titulado Alcibíades, tradicionalmente atribuido a Platón, donde representa un fallido intento de Sócrates de seducir filosóficamente al joven Alcibíades; o los Silenos de Alcibíades (Sileni alcibiadis), de Erasmo de Rotterdam, adagio en que expone por vez primera su philosophia Christi y critica el ejercicio despótico del poder ${ }^{12}$. Una vía más es la emblemática: por ejemplo, el número 8 de los Emblemas moralizados (Madrid, Luis Sánchez, 1610), de Hernando de Soto instruye sobre la fuerza de la paciencia (durum patientia frangit, "Todo lo acaba y vence la paciencia») y reflexiona sobre Sócrates y Alcibíades, el caso de Job, etc., con Plinio, Diógenes Laercio y Plutarco por fuentes. También se documenta en los Emblemas morales de Horozco y Covarrubias (III, 39, fol. 179r), y los Emblemas regio-políticos de Solórzano Pereira, que probablemente seguían la versión de Palencia, más otros autores europeos (Pérez Jiménez, 2003b); se cita en las Empresas políticas (1, p. 200) de Saavedra Fajardo, etc. Y aunque ninguno de ellos acopia la anécdota del perro que interesa, se ve cómo algunos pasajes de su biografía servían como exempla de determinados valores.

Ya en fecha posterior a Cervantes, Juan de Zabaleta dedica uno de sus Errores celebrados de la Antigüedad (1653) a reflexionar sobre la murmuración y parte de este hecho de la vida de Alcibíades:

Alcibíades, nobilísimo ateniense, compró en grande suma de dinero un perro de desusada estatura y nunca vista fiereza. A éste traía siempre consigo un bozal en la cara. Preguntóle un hombre un día para qué se acompañaba de aquel animal tan fiero, y él dijo que para echarle a los habladores, porque le enfadaban mucho. Temía Alcibíades le murmurasen algún defecto y quería tapar las bocas con esta amenaza. Testifícalo y celébralo Plutarco» (núm. 30, p. 157).

Tras el resumen condena este vicio, cuya curación no se alcanza solo con «matar al murmurador y al decidor», sino que «menester es curar las costumbres» (p. 158). El intento de Alcibíades de «amedrentar tantas lenguas mordaces con un perro era echar un lebrel a mil leones» y constituía un error

12. Respectivamente, ver Denyer (2001); Iffland (1998), sobre la autoasociación de don Quijote con Sileno (I, 15) como indicio de la cultura festiva en la novela o de su contenido trascendente. Recuerda el elogio de Alcibíades en que compara a su maestro Sócrates con los silenos («cajas pintadas con sátiros o silenos dentro de las que había estatuas de dioses») en El banquete de Platón (p. 142). Erasmo cita a Alcibíades como ejemplo de gobernante que sabe ganarse el afecto de su pueblo imitando sus costumbres en Educación del príncipe cristiano, 3, p. 106. 
porque fomentaba los ataques, imposibles de esquivar, por otra parte, dado que él «estaba en las tinieblas de los vicios» y «son tantos las tinieblas de la mala vida que ni muchos perros bastan» (p. 159). Por el contrario, ante los asedios de la murmuración Zabaleta recomienda la virtud y el perdón.

En síntesis, son muchos los caminos por los que Cervantes pudo conocer la figura de Alcibíades, pero la historia del perro únicamente pudo llegarle a través de las Vidas o las Moralia de Plutarco con sus traducciones, derivaciones y menciones en misceláneas. A partir de ahí, su ingenio hizo el resto. El hipotético uso de esta anécdota no es literal, ni mucho menos, pues no hay ninguna referencia explícita a Plutarco ni a Alcibíades en el Coloquio. Recuérdese que la tradición clásica se transmite mediante una cadena de recepciones y traducciones, y lo que corresponde a Cervantes es convertir la materia erudita en literatura original. Pues bien ¿cómo se puede relacionar este episodio de Alcibíades con la última de las Novelas ejemplares?

Reitero que no pretendo proclamar que este episodio sea el modelo sobre el que Cervantes construye la arquitectura de su novela. No obstante, hay algunas similitudes que pueden (quede clara la calidad de hipótesis) hacer pensar que tenía noticia de esta anécdota. Primeramente, al igual que el personaje griego se vale de un perro para criticar a la sociedad ateniense, Cervantes emplea dos canes parlantes para criticar a la sociedad española de su tiempo, condenando sus vicios y perversiones. Lo primero que hacen Cipión y Berganza, y que por tanto recibe el lector al comienzo, es comentar su sorprendente capacidad de lenguaje articulado y su posible origen. Esto es, al comienzo se incide en el carácter de prodigio y maravilla que supone que dos perros sean capaces de hablar. Suceso válido dentro de los esquemas del momento según la verosimilitud cristiana que logra casar la admiratio y lo verisimilis (Sáez, 2010, 2011 y en prensa). Y en su diálogo pasan revista a diversos aspectos de la sociedad áurea desde una óptica eminentemente crítica que omito por conocida.

El ardid es hábil en ambos casos, pues distrae la atención del elemento satírico al enfocar las miras respectivamente hacia la sorprendente mutilación del can y el prodigio de los perros parlantes. Es una suerte de estrategia de distracción que aclara Alcibíades y que se puede atisbar en la novelita cervantina. Y si el vitium principal al que ataca Alcibíades es la murmuración, esta es una de las lacras de la España del siglo XVII, según se dibuja en el Coloquio de los perros y en otros muchos textos coetáneos.

Igualmente, casa bien con los vínculos que la literatura cervantina mantiene con el cinismo. No se olvide que la etimología de «cínicos» en el Coloquio equivale «perros murmuradores» (p. 677), a partir del término griego kyon (Fernández Tresguerres, 2005) ${ }^{13}$. En su diálogo, los perros se muestran conscientes de su condición de comentadores de la sociedad y de sus críticas. Conocen bien los límites de la murmuración y Cipión reprende a su compañero cuando incurre en este vicio, mas sin mucho éxito. Riley mantiene que 
el cinismo de los canes en su crítica social representa «los mejores atributos de los antiguos maestros», esto es, de los fundadores de la corriente y no de sus seguidores, de donde puede razonarse que Cervantes apreciaba «las virtudes de la doctrina cínica tanto como deploraba su vicio del vituperio poco caritativo» (Riley, 2001: 234 y ss.) ${ }^{14}$. Los perros defienden una serie de valores alejados del mundo cínico (caridad, humildad, fe cristiana y conformidad) y al final del relato se unen significativamente a Mahúdes ${ }^{15}$. No en vano la preocupación moral por la sátira (legítima e ilegítima) y la crítica es constante en su obra, y le dolían los dardos que recibía de otros escritores, pero la ambigüedad, la insinuación y la moderación de corte horaciano esquivan una lectura unívoca (Close, 1990) ${ }^{16}$.

Para cerrar este rompecabezas solo falta recordar la tan comentada y profunda relación entre los cínicos, el riesgo de murmurar y los perros cervantinos, en tanto respuesta al modelo picaresco y reflexión sobre la sátira y los límites de la historia (entre la murmuración, la predicación y la filosofía) ${ }^{17}$. Pues bien, esta conexión se refuerza con el referido episodio de Alcibíades, o, si se quiere, permite apuntar - que no probar- este posible eco de la tradición clásica.

\section{FINAL}

Este es, en fin, el itinerario de un posible contacto intertextual que se ha intentado trazar. En el marco de sus lecturas, su conocimiento de Plutarco y sus variados contactos con la filosofía cínica, el Coloquio de los perros de Cervantes pudo recibir un impulso (otro más, que no exclusivo) de la anécdota

14. Apunta que los numerosos aforismos que componen El licenciado Vidriera pueden relacionarse con colecciones de apotegmas como las Vidas de los filósofos eminentes de Diógenes Laercio, y el propio protagonista es similar a Diógenes de Sínope, el primer y más célebre cínico, de quien pudo tener noticia gracias a la Vida redactada por Diógenes Laercio o la Silva de varia lección de Pero Mexía. Es interesante recordar los dos discursos que Juliano dedica al cinismo: ambos se caracterizan por la alabanza del cinismo genuino, representado por los fundadores Diógenes y Crates, a la vez que condena a los cínicos de su tiempo, que ni logran ni se esfuerzan por comprender el auténtico mensaje de la escuela a la que dicen pertenecer. Ver Candau Morón (1989). Maestro (2010: 305-306) considera que el único rasgo cínico de Cipión y Berganza es que descubren la farsa moral que reina en la sociedad aurisecular.

15. A su vez, Forcione (1982: 243 y ss.) mantiene que Cervantes reprueba la murmuración despiadada de los cínicos, de acuerdo con los planteamientos del humanismo cristiano. Molho (1983: 92) propone de forma original pero discutible que Cervantes «para narrar su representación personal del mundo, quiso adoptar una postura cínica, disfrazándose de perro». También Márquez Villanueva (1995: 258 y ss.) se ha centrado en las discusiones sobre la murmuración que oponen a ambos canes, en el marco de la interacción Alemán-Cervantes, por su similitud con las digresiones moralizantes del Guzmán de Alfarache.

16. La moderación consiste en «plantear un argumento moral en forma dialéctica» (505) y al escribir sátiras mezclaba esta especie con géneros colindantes como la novela picaresa, el apotegma, el apólogo, etc. (511).

17. Ver Oliver (1953); Riley (2001); Blasco (2005, pp. 184-187); Illades (2008); Gelz (2013). 
de los perros de Alcibíades en la que se condena la murmuración, vicio central de la antigua Grecia que en el Siglo de Oro pervivía en íntimo contacto con la sátira y la crítica socio-moral, de gran interés para Cervantes, bautizado como «Horacio cristiano» por el licenciado Márquez Torres.

\section{BIBLIOGRAFÍA CITADA}

Allés Torrent, Susanna (2008). «Alfonso de Palencia y la traducción de las Vidas de Plutarco (nuevos datos en torno al texto de partida)», Cuadernos de Filología Clásica. 28.2, pp. 99-124.

Astrana Marín, Luis (1948-1958). Vida ejemplar y heroica de Miguel de Cervantes Saavedra. Con mil documentos hasta ahora inéditos y numerosas ilustraciones y grabados de época. Madrid: Instituto Editorial Reus, 7 vols.

Barnés Vázquez, Antonio (2010). «Traducción y tradición clásica en el Quijote», Estudios Clásicos. 138, pp. 49-72.

Barnés Vázquez, Antonio (2009). «Yo he leído en Virgilio»: la tradición clásica en el Quijote. Vigo: Academia del Hispanismo.

Bergua, Jorge (1995). Estudios sobre la tradición de Plutarco en España (siglos XIIIXVII). Zaragoza: Universidad.

Blasco, Javier (2005). Cervantes, raro inventor. Alcalá de Henares: Centro de Estudios Cervantinos.

Candau Morón, José María (1989). «Juliano y los cínicos», en Actas del VII Congreso Español de Estudios Clásicos. (Madrid, 20-24 de abril de 1987). Madrid: Universidad Complutense, vol. 2, pp. 117-122.

Cervantes, Miguel de (2005). Don Quijote de la Mancha, Francisco Rico (ed.). Barcelona: Galaxia Gutenberg, 2 vols.

Cervantes, Miguel de (2005). Novelas ejemplares, Jorge García López (ed.). Barcelona: Crítica.

Close, Anthony J. (2005). «Cervantes: pensamiento, personalidad, cultura», en Miguel de Cervantes, Don Quijote de la Mancha, Francisco Rico (ed.). Barcelona: Galaxia Gutenberg, vol. 1, pp. LXXIII-XCIV.

Close, Anthony J. (1990). «Algunas reflexiones sobre la sátira en Cervantes», Nueva Revista de Filología Hispánica. 38.2, pp. 493-511.

Covarrubias, Sebastián de (2006). Tesoro de la lengua castellana o española, Ignacio Arellano y Rafael Zafra (ed.). Madrid - Frankfurt: Iberoamericana - Vervuert.

Durán López, María de los Ángeles (1991). «Alcibíades según Platón», Habis. 22, pp. 113128.

Eisenberg, Daniel (2001). «Los autores italianos en la biblioteca de Cervantes», en Alicia Villar Lecumberri (ed.), Cervantes en Italia. Actas del X Coloquio Internacional de la Asociación de Cervantistas (Roma, 27-29 septiembre 2001). Palma de Mallorca: Asociación de Cervantistas, pp. 87-92.

Eisenberg, Daniel (1991). «¿Tenía Cervantes una biblioteca?», en Elvira de Riquer (trad.), Estudios cervantinos. Barcelona: Sirmio, pp. 11-36.

Eisenberg, Daniel (1987). «La biblioteca de Cervantes», en Studia in Honorem prof. Martín de Riquer. Barcelona: Quaderns Crema, vol. 2, pp. 271-328.

Fernández Tresguerres, Alfonso (2005). «Cínicos», El Catoblepas. Revista crítica del presente. 40, p. 3. Accesible en: <www.nodulo.org/ec/2005/n040p03.htm> (14.11.2014). 
Forcione, Alban K. (1982). Cervantes and the Humanist Vision. A Study of four Exemplary Novels. Princeton: Princeton University.

Gelz, Andreas (2013). «El murmurador y la murmuración en la obra de Cervantes», Iberoromania. 78 , pp. 165-177.

Iffland, James (1998). «Don Quijote como Sileno: ¿una pista para descifrar las intenciones de Cervantes?», Anales Cervantinos. 34, pp. 135-144.

Illades, Gustavo (2007). «Sátira, prédica y murmuración: genealogía de una contienda por la voz en el Quijote de 1615», Cervantes: Bulletin of the Cervantes Society of America. 27.1, pp. 161-178.

Lasso de la Vega, José (1962). «Traducciones españolas de las Vidas de Plutarco», Estudios clásicos. 35, pp. 451-514.

Lerner, Isaías (2008). «A propósito de las lecturas de Cervantes», en Desirée Pérez Fernández (coord.), Cervantes y su tiempo. León: Universidad, vol. 1, pp. 9-17.

López Fanego, Otilia (1983). «Algo más sobre Sancho y Ricote», Anales Cervantinos. 21, pp. 221-238.

López Férez, Juan Antonio (1994). «La traducción castellana de las Vidas realizada por Alfonso de Palencia» en Manuela García Valdés (ed.). Estudios sobre Plutarco: ideas religiosas. Actas del III Simposio Internacional (Oviedo, 30 de abril al 2 de mayo de 1992). Madrid: Ediciones Clásicas, pp. 359-370.

Maestro, Jesús G. (2010). «Contra la sofística de Hillis Miller en su interpretación posmoderna de El coloquio de los perros de Miguel de Cervantes», en Jesús G. Maestro y Eduardo Urbina (ed.), Anuario de Estudios Cervantinos. Crítica, ecdótica y poética del Quijote. 6, pp. 287-312.

Márquez Villanueva, Francisco (2005). «Las bases intelectuales», en Francisco Márquez Villanueva, Cervantes en letra viva. Estudios sobre la vida y la obra. Barcelona: Reverso, pp. 48-73.

Márquez Villanueva, Francisco (1995). Trabajos y días cervantinos. Alcalá de Henares: Centro de Estudios Cervantinos.

Merkl, Heinrich (2011). Cervantes anti-sofista. Sobre Platón, Ficino y los tres Quijotes (1605, 1614 y 1615). Vigo: Academia del Hispanismo.

Mexía, Pero (2003). Silva de varia lección, Isaías Lerner (ed.). Madrid: Castalia.

Molho, Maurice (1983). «Antroponimia y cinonimia del Casamiento engañoso y Coloquio de los perros», en José Jesús de Bustos Tovar (ed.), Lenguaje, ideología y organización textual en las Novelas ejemplares. Madrid: Universidad Complutense, pp. 81-92.

Morales Ortiz, Alicia (2000). Plutarco en España: traducciones de Moralia en el siglo XVI. Murcia: Universidad.

Muñoz Gallarte, Israel (2006). «La presencia de Plutarco en España en el siglo XVI: la biblioteca del Seminario de Cuenca», en Rosa M. ${ }^{a}$ Aguilar e Ignacio R. Alfageme (ed.), Ecos de Plutarco en Europa. De Fortuna Plutarchi Studia Selecta. Madrid: Sociedad Española de Plutarquistas - Universidad Complutense, pp. 193-206.

Oliver, Antonio (1953). «La filosofía cínica y el Coloquio de los perros», Anales Cervantinos. 3, pp. 225-238.

Pérez Jiménez, Aurelio (2006). «Plutarco, Juan de Mal Lara y la galera de D. Juan de Austria», en Rosa M. ${ }^{a}$ Aguilar e Ignacio R. Alfageme (ed.), Ecos de Plutarco en Europa. De Fortuna Plutarchi Studia Selecta. Madrid: Sociedad Española de Plutarquistas - Universidad Complutense, pp. 233-246.

Pérez Jiménez, Aurelio (2005a). «Los animales de Plutarco en la emblemática europea de los siglos XVI-XVII», en J. Boulogne (ed.), Les Grecs de l'Antiquité et les animaux. Le cas remarcable de Plutarque. Lille: Université Lille 3, pp. 63-94.

Pérez Jiménez, Aurelio (2005b). «Plutarco en Alciato, I», Silva. 4, pp. 235-266. 
Pérez Jiménez, Aurelio (2003a). «El Plutarco de los Moralia en la literatura emblemática hispánica», en M. ${ }^{a}$ G. Fernández Ariza (coord.), Literatura hispanoamericana del siglo XX. Mímesis e iconografía. Málaga: Universidad, pp. 169-195.

Pérez Jiménez, Aurelio (2003b). «Las Vidas paralelas de Plutarco en la emblemática hispánica de los siglos XVI-XVII», Humanitas. 55, pp. 223-239.

Pérez Jiménez, Aurelio (2003c). «Los héroes de Plutarco como modelo en la literatura emblemática europea de los siglos XVI-XVII», en A. Barzanò et al. (ed.), Modelli eroici dall'Antichità alla cultura Europea. Roma: L'Erma di Bretschneider, pp. 375402.

Pérez Jiménez, Aurelio (1990). «Plutarco y el Humanismo español del Renacimiento», en Aurelio Pérez Jiménez y Gonzalo del Cerro Calderón (ed.), Estudios sobre Plutarco: obra y tradición. Actas del I Simposio Español sobre Plutarco (Fuengirola 1988). Málaga: Universidad, pp. 229-248.

Plato (2001). Alcibiades, Nicholas Denyer (ed.). Cambridge: Cambridge University Press. Plutarco (2006). Vidas paralelas. III, Aurelio Pérez Jiménez y Paloma Ortiz (ed. y trad.). Madrid: Gredos.

Plutarco (1999). Vidas paralelas, Emilio Crespo (ed. y trad.). Madrid: Cátedra.

Plutarco (1987). Obras morales y de costumbres (Moralia) III, Mercedes López Salvá y M. ${ }^{a}$ Antonia Medel (ed. y trad.). Madrid: Gredos.

Plutarco (1571). Morales, Diego Gracián (trad.). Salamanca: Alejandro de Cánova.

Plutarco (1491). Vidas paralelas, Alfonso de Palencia (trad.). Sevilla: Cuatro compañeros alemanes. Accesible en: <http://bibliotecadigitalhispanica.bne.es:80/webclient/Deliver yManager?pid=2941145\&custom_att_2=simple_viewer $>(17.11 .2014)$.

Ramón Palerm, Vicente (1999). «Plutarco, Cervantes y el arte de escribir historia», en José Guillermo Montes Cala, Manuel Sánchez Ortiz de Landaluce y Rafael Jesús Gallé Cejudo (coord.), Plutarco, Dioniso y el vino. Actas del VI Simposio Español sobre Plutarco (Cádiz, 14-16 de mayo de 1998). Madrid: Ediciones Clásicas, pp. 393-397.

Ravisius Textor, Johannes (1560). Officinae epitome. Lyon: Seb. Gryphius.

Riley, Edward C. (2001). «Cervantes y los cínicos (El licenciado Vidriera y El coloquio de los perros)», en Edward C. Riley, La rara invención: estudios sobre Cervantes y su posteridad literaria. Barcelona: Crítica, pp. 219-238.

Rodríguez Blanco, María Eugenia et al. (ed.) (1987). Alcibíades. Antología de textos con notas y comentarios. Madrid: Universidad Autónoma.

Rodríguez Marín, Francisco (1947). «Nuevos documentos cervantinos», en Francisco Rodríguez Marín, Estudios cervantinos. Madrid: Atlas, pp. 175-350.

Rotterdam, Erasmo de (2004). Silenos de Alcibiades, B. Pérez (trad.) y Andrea Herrán Santiago y Modesto Santos López (ed.). Salamanca: Universidad Pontificia.

Rotterdam, Erasmo de (1996). Educación del príncipe cristiano, Pedro Jiménez Guijarro y Ana Martín (ed. y trad.). Barcelona: Tecnos.

Saavedra Fajardo, Diego (1999). Empresas políticas, Sagrario López Poza (ed.). Madrid: Cátedra.

Sáez, Adrián J. (en prensa), «Ecos y referentes clásicos en el Coloquio de los perros de Cervantes», en Humanismo y Pervivencia del Mundo Clásico V. Homenaje al profesor Juan Gil (Alcañiz, 18-22 de octubre de 2010).

Sáez, Adrián J. (2011). «El "divino don de la habla": el Coloquio de los perros desde la tradición clásica y bíblica (contribución al estudio de sus fuentes)», en Christoph Strosetzki (ed.), Visiones y revisiones cervantinas. Actas selectas del VII Congreso Internacional de la Asociación de Cervantistas (Münster, 30 septiembre-4 de octubre 2009). S.1.: Centro de Estudios Cervantinos, pp. 797-806. 
Sáez, Adrián J. (2010). «Estrategias de la verosimilitud en el Coloquio de los perros», en Jesús G. Maestro y Eduardo Urbina (ed.), Anuario de Estudios Cervantinos. Crítica, ecdótica y poética del «Quijote». 6, pp. 215-228.

Sánchez Jiménez, Antonio (2011). «Del Quijote al Persiles: Rota Virgilii, fortitudo et sapientia y la trayectoria literaria de Cervantes», Rilce. 27.2, pp. 477-500.

Schwartz, Lía (2006). «Cínicos», en Carlos Alvar (ed.), Gran Enciclopedia Cervantina III. Alcalá de Henares: Centro de Estudios Cervantinos, pp. 2404-2406.

Soto, Hernando de (1983). Emblemas moralizadas, Carmen Bravo Villasante (ed.). Madrid: Fundación Universitaria Española.

Torres, José B. (2009). «¿Novela bizantina o novela helenizante? A propósito de un término consagrado», en Ignacio Arellano, Víctor García Ruiz y Carmen Saralegui (ed.), Ars bene docendi. Homenaje al profesor Kurt Spang. Pamplona: Eunsa, pp. 567-574.

Vega, María José (2003). «La poética de la lectura en el siglo XVI. Hacia una reescritura de la historia de la crítica en el Renacimiento», en Carmen Codoñer Merino (coord.), El Brocense y las humanidades en el siglo XVI. Salamanca: Universidad, pp. 255-271.

Verdegem, Simon (2010). Plutarch's Life of Alcibiades. Story, Text and Moralism. Leuven: Leuven University.

Zabaleta, Juan de (1972). Errores celebrados, David Hersbergh (ed.). Madrid: Espasa Calpe.

Recibido: 6 de octubre de 2012

Aceptado: 9 de diciembre de 2013

\title{
Resumen
}

En el marco de la intertextualidad clásica cervantina, se recuerdan primeramente los lazos de Cervantes con Plutarco para después tratar de poner en relación una anécdota de la biografía de Alcibíades (Vidas paralelas) contra la murmuración con la ficción del Coloquio de los perros, con la que comparte una serie de rasgos.

Palabras clave: Cervantes; Plutarco; cínicos; Alcibíades; Coloquio de los perros.

Title: «More on Cervantes, Plutarch and the Cynics: an Anecdote about Alcibiades and the Dialogue of the Dogs"

\begin{abstract}
In the context of the classical intertextuality of Cervantes' work, first the links between Cervantes and Plutarch are reminded, in order to try to connect an anecdote about the Alcibiades' biography (Parallel Lives) against gossip with the fiction of the Dialogue of the Dogs, whith which it has some characteristics in common.
\end{abstract}

Key words: Cervantes; Plutarch; Cynics; Alcibiades; Dialogue of the Dogs. 